\title{
Vagus Nerve Stimulation is an Ideal Therapeutic Candidate for COVID-19 Infection
}

Patrick Nemechek*

Nemechek Autonomic Medicine, Verrado Way Suite, Buckeye, Arizona, USA

${ }^{*}$ Corresponding author: Patrick Nemechek, Nemechek Autonomic Medicine, 4252 N Verrado Way Suite 200, 85396 Buckeye, Arizona, USA, E-mail:dr@autonomicmed.com

Received: 28 May, 2020 | Accepted: 04 Jun, 2020 | Published: 11 Jun, 2020

Citation: Nemechek P (2020) Vagus Nerve Stimulation is an Ideal Therapeutic Candidate for COVID-19 Infection. J Emerg Dis Virol 5(2): dx.doi.org/10.16966/2473-1846.152

Copyright: (C) 2020 Nemechek P. This is an open-access article distributed under the terms of the Creative Commons Attribution License, which permits unrestricted use, distribution, and reproduction in any medium, provided the original author and source are credited.

\section{Introduction}

Vagus nerve stimulation is an unrecognized therapeutic tool that may be capable of modulating the cytokine storm as well as the coagulation abnormalities in COVID-19 infection.

The pathophysiology of severe acute respiratory syndrome in many hospitalizedCOVID-19 patients includes the development of Acute Respiratory Distress Syndrome (ARDS) and high inflammatory markers suggestive of a cytokine storm. Serum cytokines measured in Chinese COVID-19 patients were significantly higher in severe compared to moderate cases, specifically the pro-inflammatory cytokines interleukin 2R (IL-2R), IL-6, IL-10, and Tumor Necrosis Factor a (TNF- $\alpha)$ [1]. Maximal levels of IL- 6 followed by CRP (C-reactive protein) are also highly predictive of the need for mechanical ventilation [2].

\section{Hypothesis}

Electrical stimulation of the Vagus Nerve (VNS) can improve the body's natural ability to regulate the inflammatory response and may be potent enough to suppress pro-inflammatory cytokines and prevent death from COVID-19, especially if used early in the course of hospitalization [3]. The vagus nerve also modulates lung inflammation via the pulmonary parasympathetic inflammatory reflex [4]

\section{The Challenge}

Risk factors for severe COVID-19 include conditions associated with chronic inflammation such as chronic respiratory and cardiovascular disease, hypertension, diabetes, obesity, smoking, and old age (inflammaging) (Figure 1).

The overproduction of proinflammatory cytokines can also lead to an increased risk of coagulopathies, vascular hyperpermeability, multiorgan failure, and eventually death when the high cytokine concentrations are unabated over time [5].
The loss of control of the coagulation cascade from intense in flammation leads to an imbalance of procoagulant-anticoagulant factors and predisposes the patient to the development of micro thrombosis, disseminated intravascular coagulation, and multiorgan failure. This is evidenced in severe COVID-19 pneumonia in which raised d-dimer concentrations indicate a poor prognostic feature along with disseminated intravascular coagulation common in non-survivors [6].

\section{Supporting Evidence}

Human studies demonstrate that VNS is effective in suppressing a range of pro-inflammatory cytokines including IL-6, IL-1, TNF, CRP and improves clinical symptoms in rheumatoid arthritis, intractable epilepsy, atrial fibrillation, and Crohn's Disease [7]. In animal studies, VNS is capable of inhibiting the activation of coagulation and fibrinolysis during LPS endotoxemia in rats [8].

These findings suggest that VNS may be effective in treating disorders characterized by cytokine dysregulation and that it has the potential to prevent hospitalized patients with COVID-19 from progressing to respiratory failure and death.

The vagus nerve can be stimulated by applying a mild electrical current over the auricular branch of the vagus nerve which can be found within the concha or across the tragus of the ear (transcutaneous auricular VNS; taVNS). Stimulation of afferent vagus nerve fibers in the ear activates the inflammatory reflex which in turn regulates the proper working point of the immune response [9].

taVNS is simple to use, requires minimal training, and is inexpensive. Based on its scientific success in modulating immune reactions, taVNS may prevent and even counteract the cytokine storm observed among some hospitalized COVID-19 patients.

\section{Potential Benefits}

These unrecognized effects of VNS on the cholinergic anti- 


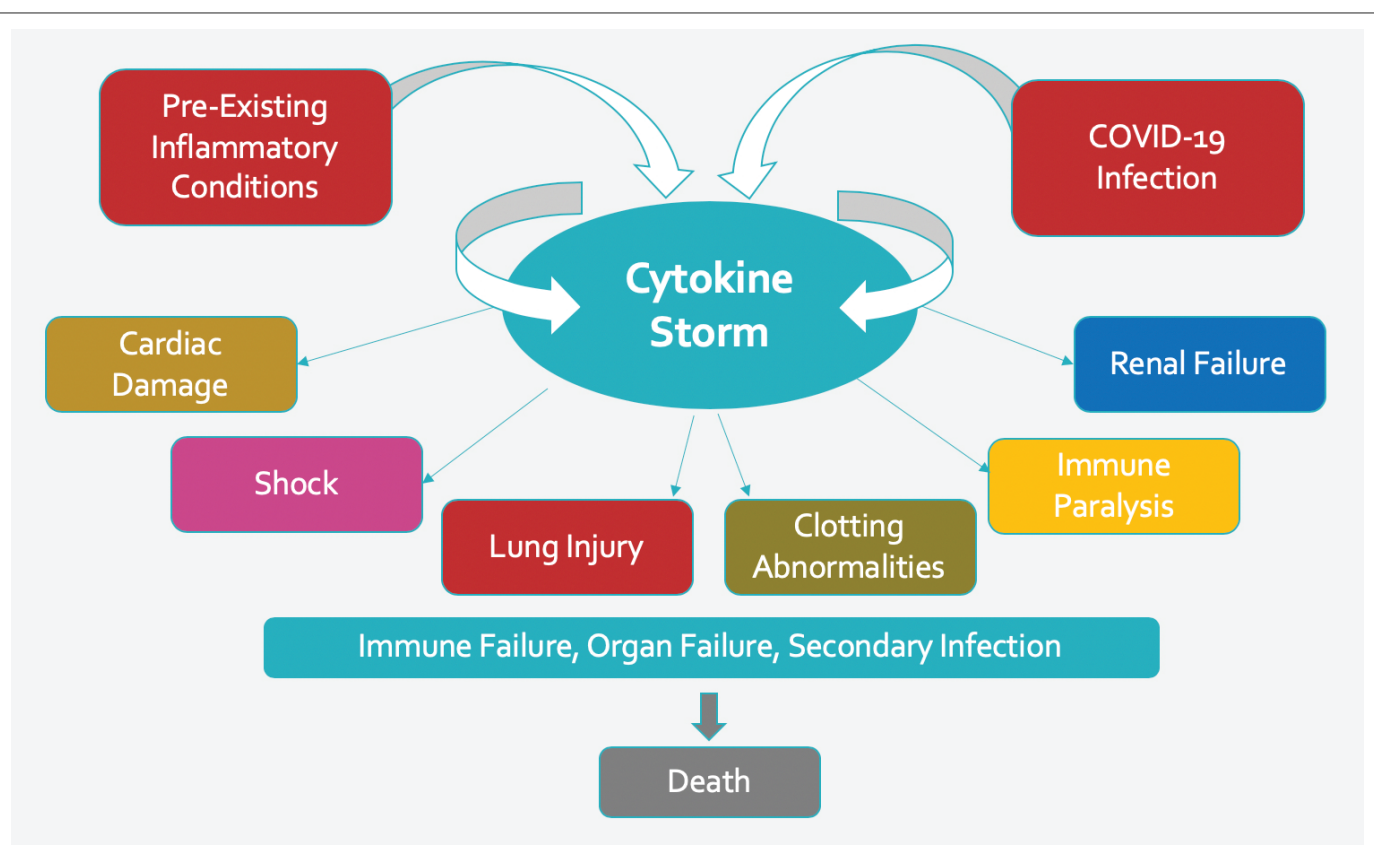

Figure 1: Potential elements of the cytokine storm with COVID-19 infection.

inflammatory pathway as well as the coagulant-anticoagulant balance make it an ideal therapeutic candidate for COVID-19 infections.

\section{References}

1. Chen G, Wu D, Guo W, Cao Y, Huang D, et al. (2020) Clinical and immunologic features in severe and moderate Coronavirus Disease 2019. J Clin Invest 130: 2620-2629.

2. Herold T, Jurinovic V, Arnreich C, Lipworth BJ, Hellmuth JC, et al. (2020) Elevated levels of interleukin- 6 and CRP predict the need for mechanical ventilation in COVID-19. J Allergy Clin Immunol S00916749: 30685-30690.

3. Kaniusas E, Kampusch S, Tittgemeyer M, Panetsos F, Gines RF, et al. (2019) Current Directions in the Auricular Vagus Nerve Stimulation I-A Physiological Perspective. Front Neurosci 13: 854.

4. Wu H, Li L, Su X (2014) Vagus nerve through $\alpha 7$ nAChR modulates lung infection and inflammation: models, cells, and signals. Biomed Res Int.
5. Meduri GU, Kohler G, Headley S, Tolley E, Stentz F, et al. (1995) Inflammatory cytokines in the BAL of patients with ARDS. Persistent elevation over time predicts poor outcome. Chest 108: 1303-1314.

6. Tang N, Li D, Wang X, Sun Z (2020) Abnormal coagulation parameters are associated with poor prognosis in patients with novel coronavirus pneumonia. J Thromb Haemost 18: 844-847.

7. Koopman FA, Chavan SS, Miljko S, Grazio S, Sokolovic S, et al. (2016) Vagus nerve stimulation inhibits cytokine production and attenuates disease severity in rheumatoid arthritis. Proc Natl Acad Sci USA 113: 8284-8289.

8. van Westerloo DJ, Giebelen IA, Meijers JC, Daalhuisen J, de Vos AF, et al. (2006) Vagus nerve stimulation inhibits activation of coagulation and fibrinolysis during endotoxemia in rats. J Thromb Haemost 4: 1997-2002.

9. Pavlov VA, Tracey KJ (2012) The vagus nerve and the inflammatory reflex-linking immunity and metabolism. Nat Rev Endocrinol 8: 743754. 